\title{
Professor Age and Gender Affect Student Perceptions and Grades
}

\author{
Shauna W. Joye ${ }^{1}$ and Janie H. Wilson ${ }^{2}$
}

\begin{abstract}
Student evaluations provide rich information about teaching performance, but a number of factors beyond teacher effectiveness influence student evaluations. In this study we examined the effects of professor gender and perceived age on ratings of effectiveness and rapport as well as academic performance. We also asked students to rate professor attractiveness as a potential explanation for group differences. Participants $(N=308)$ saw a picture of either a young or old male or female professor while listening to an audio lecture. Students reported greater perceived rapport and attractiveness with the female relative to the male professors and for younger versus older professors. However, students reported the male professors as more effective than the female professors. An interaction revealed that among female professors only, younger women were rated as more attractive than comparison conditions. Thus, age and gender bias likely impact student evaluations of teaching. Our study also revealed higher quiz grades in the older-female condition.
\end{abstract}

Keywords: student evaluations, professor age, professor gender, rapport, student grades

Student evaluations help professors consider changes such as teaching style, course content, and classroom policies in an effort to help students learn and retain information. The opportunity for reflection is perhaps the most powerful benefit of evaluations. At many colleges, evaluations also are used to determine raises, promotions, tenure, and even teaching awards. In support of widespread use, data indicate that teaching evaluations can be good indicators of teaching effectiveness (e.g., Marsh \& Roche, 1997; Remedios \& Lieberman, 2008).

However, numerous factors beyond teacher effectiveness influence student evaluations. For example, variables such as a student's prior interest in the subject matter, expected grade in the course, and reason for taking the course reside within the student and are outside of an instructor's control. In a review of the literature, Marsh and Roche (1997) found that these and other factors affected student evaluations of teachers, and although some effect sizes were small, variability in evaluations is troublesome. Many contextual variables that impact student evaluations also are, for the most part, outside of the instructor's control. For example, class size, classroom setup, availability of technology, distractions outside the classroom, and larger contextual issues such as natural disasters, war, or terrorist activity (e.g., 9-11) might influence student evaluations. Instructors must contend with variability in teaching evaluations based on student and contextual variables, recognizing that negative emotions may become associated with the course and teacher.

Unfortunately, student evaluations may also vary based on characteristics of instructors themselves, such as their gender, age, and attractiveness. For the most part, these variables are

\footnotetext{
${ }^{1}$ Department of Psychology, Georgia Southern University, 2670 Southern Drive; Statesboro, GA 30458, sjoye@georgiasouthern.edu.

${ }^{2}$ Department of Psychology, Georgia Southern University, Statesboro, GA.
} 
unchangeable and yet create bias in evaluations. Student perceptions likely tap into cultural norms related to gender, age, and attractiveness. For example, women are expected to be kind (Ebert, Steffens, \& Kroth, 2014), agreeable, open, and contentious (Löckenhoff, 2014), and both men and women are expected to be competent (Löckenhoff, 2014). In the teaching realm, Kierstead, D’Agostino, and Dill (1988) found that whereas male professors earned high student evaluations if they demonstrated competence, female professors had to demonstrate both competence and warmth to obtain the same high ratings. Similarly, youth is associated with more liking (Danziger \& Welfel, 2000). In the classroom, Horner, Murray, and Rushton (1989) found a negative correlation between instructor age and ratings of teaching effectiveness $(r=-.33)$. Likewise, Wilson, Beyer, and Monteiro (2014) used images of young and old adults and found that older professors received more negative ratings on perceptions of friendliness and rapport than younger professors. An interaction between gender and age showed that students rated an older woman as less organized than a younger woman, although male professors were rated the same regardless of age.

Perhaps tied to age, attractiveness is tied to positive perceptions. Allport (1954) asserted that society wants to believe in a just world. Individuals want to believe that people get what they deserve. Relatedly, the belief is that physically beautiful people have somehow earned beauty by embodying good qualities (i.e., “what is beautiful is good;” Dion, Berscheid, \& Walster, 1972). Specifically in research on the scholarship of teaching and learning, more attractiveness has been linked to higher overall student ratings (e.g., Riniolo, Johnson, Sherman, \& Misso, 2006), higher ratings of teacher effectiveness (Felton, Mitchell, \& Stinson, 2004), better course quality (Felton, Koper, Mitchell, \& Stinson, 2008), higher grades (Gurung \& Vespia, 2007), and perceptions of being more approachable, likeable, and providing a more enjoyable class (Gurung \& Vespia, 2007). In a large-scale study of online ratings of professors $(N=2281)$, Freng and Webber (2009) found that even after controlling for a number of other factors, professor attractiveness still accounted for $8 \%$ of the variance in student ratings. Hamermesh and Parker (2005) suggested that more positive ratings may relate with more learning if students focus more intently on attractive professors, remaining more engaged and earning higher grades.

As the above studies indicate, student perceptions are influenced by instructor gender, age, and attractiveness. However, the bulk of research asks students to evaluate professors with whom they have interacted. The richness of social interactions brings nuisance variability associated with a number of variables, including instructor experience, skill, and warmth, that potentially covary with less changeable instructor characteristics. For example, positive social interactions may actually lead students to provide higher evaluations over time. In fact, even in the absence of positive experiences with the instructor, repeated exposure to a stimulus results in more positive attitudes toward that stimulus (see Bornstein, 1989, for a review of the Mere Exposure Effect; Zajonc, 1968). Further, the complexities of the classroom do not allow isolation of variables such as instructor gender, age, and attractiveness.

In an attempt to remove influences of repeated and varied interactions as well as isolate variables, Goebel and Cashen (1979) focused on age and attractiveness. They asked students to look at photographs of professors and complete student evaluations. Students expected less friendliness and poorer organization from older teachers than younger teachers. Students also rated the more attractive professors as friendlier, more encouraging, more organized, less likely to give too much work, and better professors overall than the unattractive professors. Thus, instructor beauty influences student perceptions and expectations when no additional information is provided. When evaluating professors, indeed, what is beautiful is good. 
Wilson and colleagues (2014) extended research outside of the classroom by showing students photographs of younger and older professors. Students rated younger professors as more attractive than older professors, revealing a bias toward youth. This societal perception is pervasive, with youth typically seen as more attractive (Bargh, Chen, \& Burrows, 1996; Zebrowitz, Olson, \& Hoffman, 1993). Because attractiveness relates with higher teaching evaluations, older professors may suffer.

Of course cultural expectations of attractiveness across the lifespan differ for men and women. A youthful appearance among women is particularly valued, with younger women seen as more attractive than older women (Sarwer, Grossbart, \& Didie, 2003). Although Wilson and colleagues (2014) found higher student ratings of attractiveness for younger professors, the effect was driven by ratings of female pictures. In an interaction, younger female professors were rated as more attractive than older female professors; this effect was not seen for male professors. Based on these data, older female professors may experience the most bias in teaching evaluations if they are seen as unattractive by a society valuing youth.

Interestingly, even when beauty cannot be assessed, instructor age and gender influences student evaluations. Arbuckle and Williams (2003) showed students a computer-generated gender-neutral stick figure presenting a 35-minute lecture in a gender-neutral voice. They asked students to identify the stick figure as either male or female and old or young as well as evaluate the lecture. Of the four possible professor age/gender groups, when students perceived the stick figure as a young male professor, they rated the figure as speaking more enthusiastically and using a meaningful tone of voice.

The available literature suggests that instructor gender and age influence evaluations even when students have only a picture or a stick figure on which to base judgments. Researchers might argue that such studies have limited external validity. Conversely, classroom studies may be influenced by the ongoing, dynamic nature of professor-student interactions, reducing internal validity. In the current study, we provided photographs of professors as well as additional classroom-related information in the form of a lecture. Students viewed either a male or female professor who was either young or old, listened to and completed a quiz on a brief lecture, and then rated the professors on attractiveness, effectiveness, and rapport. Our hypotheses were as follows:

1. We expected professor gender to affect student expectations of instructor effectiveness, with higher effectiveness ratings for the male professors, regardless of age, than female professors.

2. We expected professor gender and age to affect ratings of the instructor, with higher ratings of attractiveness and rapport expected for the younger female professor.

3. Finally, grades were expected to be higher for the young female instructor based on the supposition (Hamermesh \& Parker, 2005) that students' focus is enhanced by attractiveness.

\section{Method}

\section{Participants}

In this study, 340 (127 men and 213 women) students from a southeastern university participated. Our sample consisted of 242 white participants, 75 black participants, and 23 minorities including Asian, Native American, Hispanic, and mixed ethnicities as well as no 
Joye, S. and Wilson, J.

response to this demographic item. The average age of our sample was 19.88 years old $(S D=$ 2.79). The majority of participants were enrolled in an introductory psychology course, although students in additional psychology courses were invited to participate if their instructor allowed credit. All students signed up to participate using an online participant-management system, after which they received a link to an online study hosted by Qualtrics. We received IRB approval prior to running the study, and all students were treated ethically. Of the original 340 participants, 308 completed the entire survey and remained in the data set.

\section{Materials}

Two pictures of "instructors" were chosen from a web search of publically available pictures. Both images were then digitally altered to make each of them appear older (i.e., wrinkles and lighter hair color), for a total of four images. We used black-and-white, highquality pictures of the head and neck only.

The lecture was a three-minute audio file about the history of Bedlam Hospital in London. A 16-year-old boy prepared the audio file, and digital alteration increased the frequency to create a gender-ambiguous audio that could feasibly represent both ages and genders of "instructors." At the beginning of the Qualtrics survey, students were told that they would hear a file that was digitally altered. Thus, the artificial sound of the file should have been explained, allowing students to "buy in" to the gender implied by the instructor's picture they viewed. Before the lecture began, students read that they would be quizzed on lecture material. A 10item, true-false quiz assessed learning based on lecture content.

Perceptions of the professor effectiveness were assessed using measures from both Goebel and Cashen (1979) and Wilson and colleagues (2014). These included seven items of teacher effectiveness, including the teacher encouraging questions, expecting good work, assigning too much work, being organized, explaining concepts, behaving in a friendly manner toward students, and overall being a good teacher. For each item, ratings ranged from 1-5, with 1 representing "Strongly Disagree," 2 indicating "Disagree," 3 rating "Neither Agree nor Disagree,” 4 representing “Agree,” and 5 indicating "Strongly Agree.” Based on prior research, these items were not consolidated but instead served as separate measures of teacher effectiveness.

Students also completed the Brief Professor-Student Rapport Scale. The scale contains six items that assess student perceptions of rapport with an instructor. Five-point ratings range from Strongly Disagree to Strongly Agree; two of the items are reverse scored. We altered the wording slightly by asking students to rate how they thought the professor in the picture would behave rather than indicate how an existing professor did, in fact, behave. For example, "My professor makes class enjoyable" was changed to "This instructor would make class enjoyable." The brief version of the scale shows good convergent and discriminant validity with other measures of rapport (Ryan \& Wilson, 2014) and correlates with numerous positive student outcomes, including student motivation, number of classes missed, attitudes toward the professor and course, and learning, including end-of-term grades (Wilson \& Ryan, 2013). We used average ratings in data analyses.

Attractiveness of the pictured person was rated using one item: "How attractive do you think this instructor is?" rated on a 7-point Likert scale from Very Unattractive to Very Attractive. Students also rated their perception of the teacher's age in years by answering the item: "How old do you think this instructor is?" 
Joye, S. and Wilson, J.

\section{Procedure}

Participants clicked on a link to the survey and indicated their agreement to continue by clicking the bottom of an informed-consent form. Next they saw one of four instructor pictures randomized based on the computer program: adult man, older adult man, adult woman, and older adult woman. Near the picture was a standard bar for an audio file with an iconic Play button. In bold below the box, students learned that the voice they would hear had been digitally altered. They were instructed to listen to the entire lecture because they would be quizzed on the material immediately following the lecture.

After listening to the lecture and completing the quiz, students completed the seven professor assessments used by Goebel and Cashen (1979) and Wilson and colleagues (2014). Next, participants completed the Brief Professor-Student Rapport Scale. The picture remained above the scale when completing ratings. On the next page, the picture again appeared at the top, and students were asked to indicate perceived age of the instructor and attractiveness. Lastly, students provided basic demographic information on themselves.

\section{Results}

\section{Manipulation Check}

We intended to create the impression of young versus old male and female professors. Our manipulation check revealed that we did create the intended perceptions based on a significant difference between assume ages of professors, $F(1,304)=148.13, p<.001$, partial $\eta^{2}$ $=.33$. Students rated the digitally-altered "older" pictures as older $(M=43.49$, SEM $=.49, n=$ $151)$ than the unaltered "younger" pictures $(M=35.46, S E M=.49, n=157)$. However, we also noted that instructor gender influenced assumed age, $F(1,304)=17.99, p<.001$, partial $\eta^{2}=.06$, with men viewed as older $(M=40.72, S E M=.55, n=158)$ than women $(M=38.00, S E M=.61$, $n=150)$. Further, instructor gender and aging of pictures interacted to affect assumed age, $F(1$, $304)=9.87, p=.002$, partial $\eta^{2}=.03$. The aged pictures were perceived to be older than the younger pictures for both the male professor ( $M$ for old $=43.86, S E M=.69, n=76$; $M$ for young $=37.82, S E M=.71, n=82$ ) and the female professor ( $M$ for old $=43.12, S E M=.70, n=75 ; M$ for young $=32.88, S E M=.53, n=75$ ). Additionally, the young male professor was seen as older than the young female professor. Pictures of the older male and female instructors did not differ $(p>.05)$.

\section{Collapsing Data}

Although our manipulation check revealed that images altered to communicate an older professor did cause students to estimate a higher age relative to the younger images, the perceived ages differed by only 2.84 years based on variability within conditions. Further, the male instructor was seen as older than the female instructor, particularly in pictures intended to communicate youth, even though the pictures were intended to create perceptions of similar age. Because student perceptions of instructor age were our primary concern, and perceived age relates to student ratings of teaching effectiveness (Arbuckle \& Williams, 2003), we divided 
Joye, S. and Wilson, J.

participants into two groups based on participants' perceptions of the instructor as up to 40 years old or above 40 (median-split procedure using perceived age across the entire data set).

Of the group in which the man was intended to look young, 49 participants assumed he was, in fact, at or below 40 years old; however, 33 students perceived him as over 40 . In the male picture intended to look older, 66 students assessed him as over 40, and only 10 assumed he was 40 years old or less. Of female pictures, the younger image revealed a good student match with expected and perceived age, with 67 assuming she was 40 or younger; only 8 thought she was older than 40. Finally, the picture of the older female was perceived as above 40 by 59 participants and up to 40 years old by 16 participants.

The final analysis contained 77 participants perceiving a younger male professor, 81 perceiving an older male professor, 94 perceiving a younger female professor, and 56 perceiving an older female professor.

\section{Primary Analysis}

We analyzed these data using a 2 (gender of professor) X 2 (perceived age of professor), between-groups MANOVA. Dependent variables of interest included seven items related to teacher effectiveness as well as the Brief Professor-Student Rapport Scale (Wilson \& Ryan, 2013), the attractiveness rating, and quiz grades in percent correct.

Omnibus tests allowed us to further examine effects for gender of the instructor pictured, perceived age of the instructor, and the interaction (below, all $p<.05$ ). Gender of the instructor affected scores on student perceptions of the instructor's ability to explain material well, $F(1$, $304)=3.86, p=.05$, partial $\eta^{2}=.013$, brief rapport $F(1,304)=12.54, p=.001$, partial $\eta^{2}=.043$, attractiveness, $F(1,304)=88.53, p<.001$, partial $\eta^{2}=.23$, and quiz grades, $F(1,304)=4.30, p$ $=.039$, partial $\eta^{2}=.014$. Regardless of perceived age, the male instructor was rated as better at explaining the material $(M=3.41, S E M=.08)$ than the female instructor $(M=3.16, S E M=.09)$. However, the female instructor was assumed to foster more rapport $(M=3.42, S E M=.05$ than the male instructor $(M=3.17, S E M=.04)$, and she was rated as more attractive $(M=4.74, S E M$ $=.10)$ than the male instructor $(M=3.48, S E M=.09)$. Finally, students earned higher grades on the lecture quiz when they viewed a female professor $(M=59.04, S E M=1.27)$ versus viewing a male professor $(M=55.43, S E M=1.19)$.

Perceived age of the instructor, regardless of gender, affected student perceptions of professor-student rapport, $F(1,304)=13.84, p=.001$, partial $\eta^{2}=.044$, attractiveness, $F(1,304)$ $=19.21 . p=.001$, partial $\eta^{2}=.059$, and quiz grades, $F(1,304)=7.79, p=.006$, partial $\eta^{2}=.025$. Students rated younger instructors as more attractive $(M=4.40$, SEM =.09) than older instructors $(M=3.82, S E M=.10)$ and assumed more rapport with the younger instructor $(M=$ $3.23, S E M=.05)$ than the older instructor $(M=2.93$, SEM = .06). Interestingly, students scored significantly higher on a quiz of the lecture material if they believe the lecture to come from an older professor $(M=59.66$, $S E M=1.30)$ versus a younger one $(M=54.81$, $S E M=1.15)$.

Attractiveness and quiz-grade outcomes were further explained by an interaction between instructor gender and perceived age, $F(1,304)=11.83, p=.001$, partial $\eta^{2}=.037$, and $F(1,304)$ $=4.93, p=.027$, partial $\eta^{2}=.016$, respectively. As seen in Figure 1 , across pictures of the female professor, the younger picture was rated as more attractive $(M=5.26, S E M=.12)$ than the older picture $(M=4.21$, SEM = .15). Ratings of male attractiveness did not vary with age $(p>.05)$. On the quiz outcome, students earned higher scores when they thought they were hearing from an older female $(M=63.39$, $S E M=2.00)$ than a younger female $(M=54.68, S E M=1.55)$ as well as 
compared with the older male $(M=55.93$, SEM = 1.67). When both the male and female instructors were considered to be young, quiz scores did not differ ( $p>.05$; see Figure 2.)

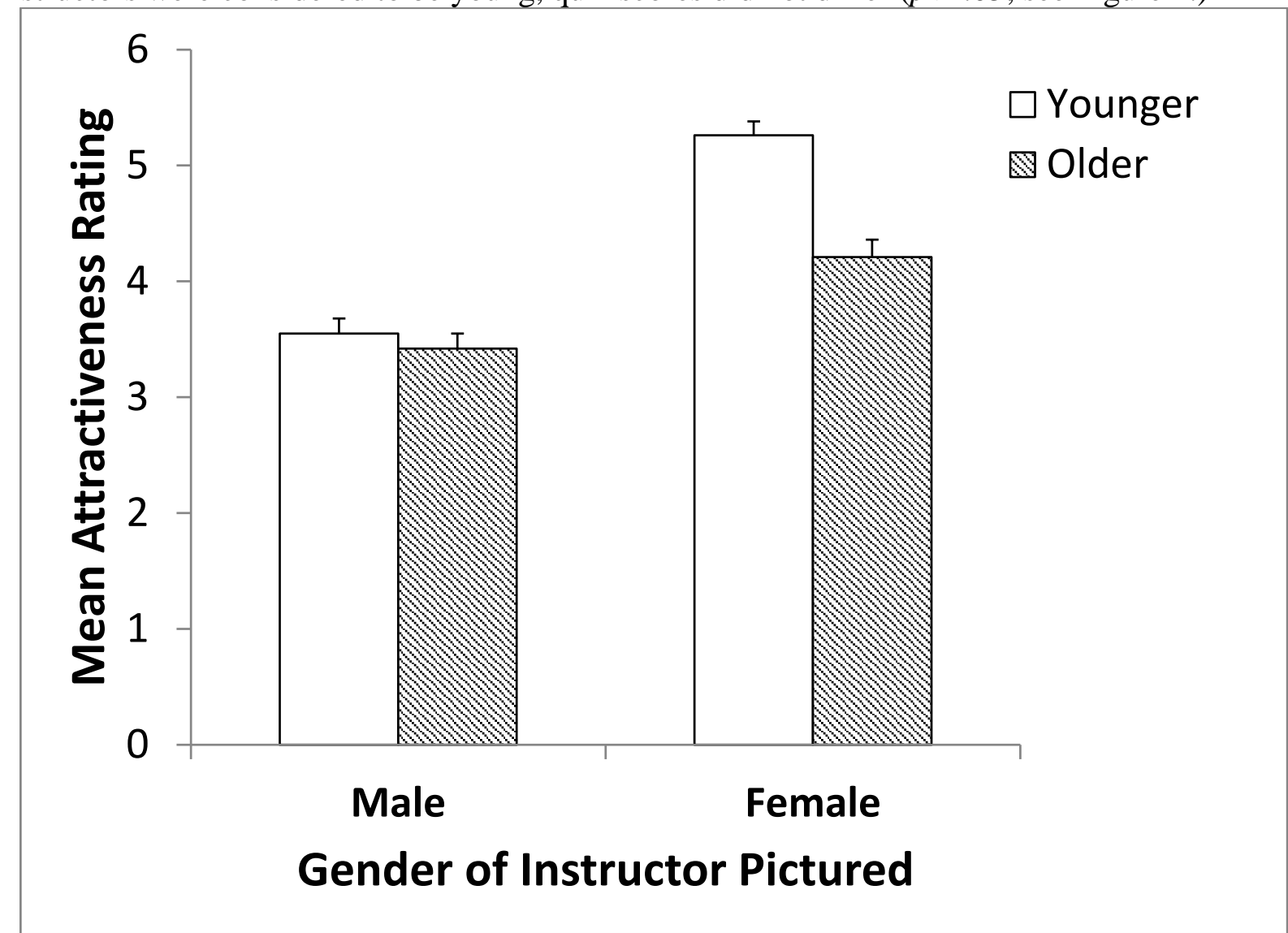

Figure 1. Participants rated a younger female instructor (perceived as up to 40 years old) as more attractive than an older version of the same instructor. Perceptions of male instructors did not differ based on age. Error bars represent SEM. 


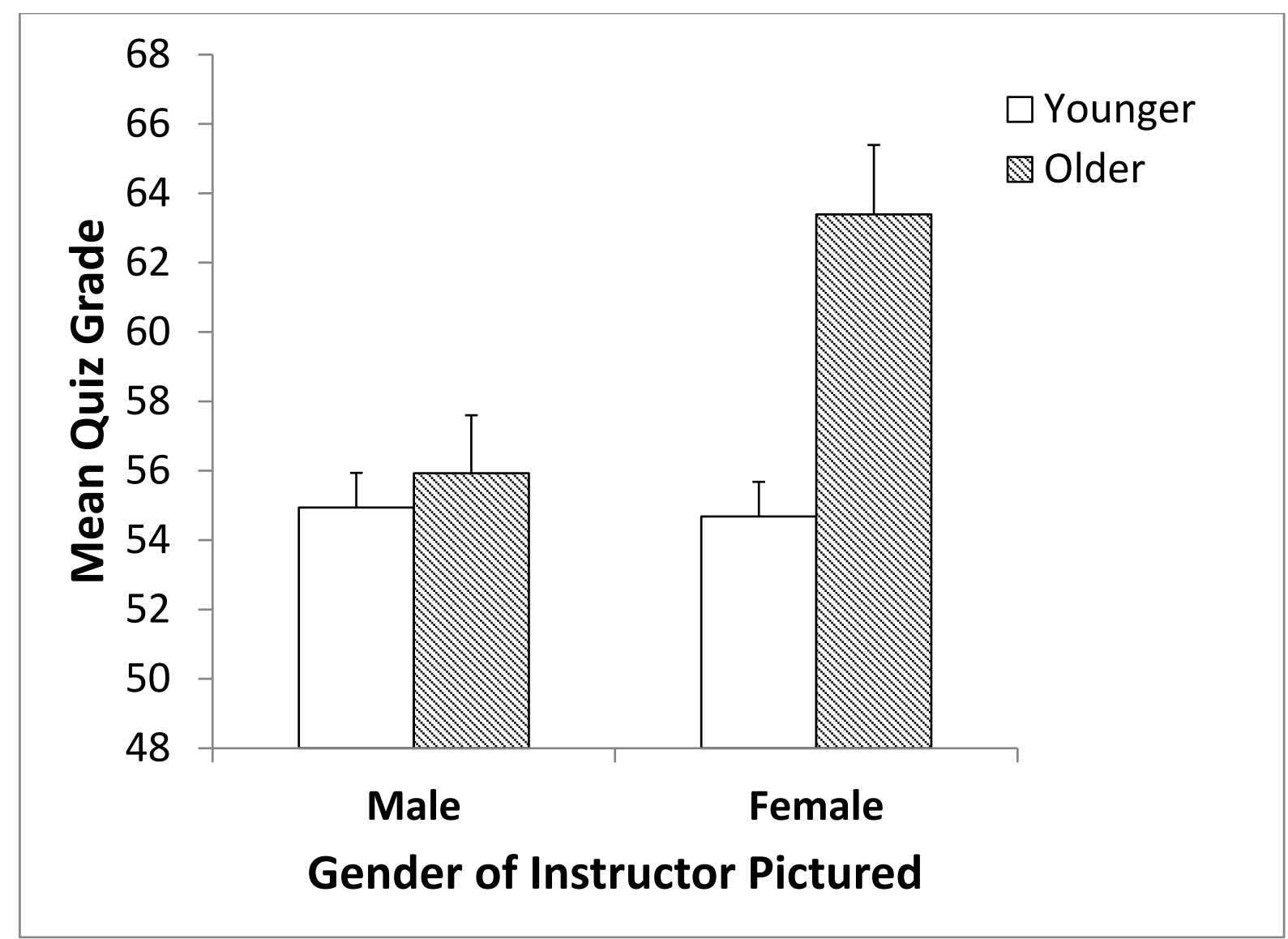

Figure 2. Participants earned better quiz grades on a lecture they perceived to be given by an older female instructor than either a younger female instructor or an older male instructor. Error bars represent SEM.

\section{Discussion}

Our first hypothesis was that students would rate the male professor in the current study as more effective than the female professor, regardless of age. This hypothesis was supported. Of the seven separate items measuring effectiveness, explaining concepts arguably serves as the clearest indication of effective teaching, and this item reflected student perceptions in favor of male instructors. Our second hypothesis was that whereas the younger female professor would earn higher ratings of attractiveness and rapport than the older female professor, this effect would not be seen for male professors. This hypothesis was partially supported. Results were as expected for attractiveness, but for rapport, there were overall effects for gender and age (with younger and female professors being seen as engendering higher rapport), but these variables did not interact. Our third hypothesis that the younger female professor would inspire higher grades was not supported. In fact, participants who perceived an older female professor scored higher on the quiz.

Students expect male professors to be effective in their work but expect female professors to spend time building supportive relationships with students. According to Kierstead, D’Agostino, and Dill (1988), male professors earned better student evaluations if they demonstrated competence, but female professors had to demonstrate both competence and warmth to obtain the same high ratings. Unfortunately, failure to behave as gender roles dictate 
(according to students) results in greater hostility toward female professors, in particular (Sprague \& Massoni, 2005) and may also result in poorer evaluations. Professors who behave in a way to support expectations are rewarded in student evaluations.

In our study, perhaps higher rapport ratings for female professors can be explained by higher ratings of attractiveness. Goebel and Cashen (1979) found that students perceived more attractive professors as friendlier, more encouraging, more organized, less likely to give too much work, and better professors overall than unattractive professors. Perhaps it is not women who are expected to be warm but attractive people who are expected to be warm. To test this potential explanation, we examined the correlations between attractiveness and rapport based on the female pictures, $r(148)=.24, p=.003$, and male pictures, $r(156)=.23, p=.003$, both of which yielded significant relationships. However, the large sample size influenced our ability to find significance, and the correlational values were weak to moderate. Certainly, attractiveness explains some variability in rapport, but we cannot say with confidence that gender of the professor did not further explain student ratings of rapport.

Likewise, students rated younger professors as more attractive and warmer (higher rapport) than older professors. In fact, perceived age correlated negatively with rapport, $r(306)=$ -.27, $p<.001$, and ratings of attractiveness, $r(306)=-.31, p<.001$. These results are not surprising given societal norms. Lucăcel and Băban (2014) asked participants in their twenties about perceptions on aging and found that the majority of people in their sample held a negative perception of old age and the aging process. Similarly, individuals under 35 years are less likely to believe that older people can be as effective as younger workers (Abramson \& Silverstein, 2004). Our study suggests that ageist attitudes are not discarded at the classroom door. Students expect older professors to be less effective teachers.

In addition to student perceptions, we directly measured learning with a lecture quiz. We expected attractiveness, rapport, and grades to correlate positively with each other based on Hamermesh and Parker's (2005) argument that students focus more on attractive teachers. However, we found significantly better recall when students thought the lecturer was an older female. This result is particularly surprising because students rated the older female as less attractive than the younger female. Students chose to focus most on a lecture provided by a female they perceived to be over 40 years old.

An older female could activate a schema for "mother," a female likely to expect a strong work ethic. Students' desire to please a mother figure could increase focus during a brief lecture. Indeed, based on a significantly higher quiz grade, we must assume more focus. Higher quiz averages for those perceiving an older woman may indicate that students work harder for older women than younger women or men. This idea is supported by the fact that although perceived age and quiz grades correlated significantly in the overall sample, $r(306)=.16, p=.006$, this correlation was driven by female professors, $r(148)=.27, p=.001$. For male professors, the correlation between perceived age and quiz grades failed to reach significance, $r(156)=.07, p>$ .05. Based on the positive relationship between quiz grades and perceived age of the female professor, activating a schema for "mother" may explain higher grades.

Taken together, results of the current study reveal the impact of professor gender and age on student evaluations of teaching and grades. As instructors, we would benefit from minimizing potential negative effects reported here and maximizing benefits associated with professor gender and age. For example, Legg and Wilson (2009) found that when students received an emailed welcome message one week prior to the first day of class, motivation, attitudes toward 
the instructor, and retention were enhanced. Although students may be able to guess a professor's gender based on a name, an email can attenuate the impact of age.

Professors can also improve students' early impressions on the first day of class. For example, professors might have what students consider an "ideal" first day, which includes covering the syllabus in a welcoming manner, avoiding homework, and ending class early. Although some may argue that ending class early on the first sets a "lazy" tone for the remainder of the course, Wilson and Wilson (2008) found that following students' wishes for the first day of class improved both student motivation and end-of-term grades. As another first-day activity, welcoming students by shaking hands increased ratings of instructor skill and ability to motivate students (Wilson, Stadler, Schwartz, \& Goff, 2009). We should caution that this effect occurred for female professors only; for male professors, the opposite effect was seen. Certainly, many approaches can enhance students' perceived effectiveness related to female instructors and rapport related to male instructors as well as older professors.

How does the current study inform the use of teaching evaluations for professor tenure, promotion, raises, and awards? Traditional measures focus on student perceptions, not student performance. As a result, older female professors may be at a disadvantage. The practice of rewarding or punishing faculty based on student evaluations may be unfair if biases exist. In the case of the older female professor, she may be highly effective at helping students learn even if her teaching evaluations are relatively low.

\section{Potential Limitations and Suggestions for Future Research}

A potential limitation in this study is the fact that most students in this study were in an introductory psychology course. It is quite possible that more advanced students work through their expectations of others and learn to avoid bias. Unfortunately, a wealth of research suggests that bias, whether explicit or implicit, exists within people regardless of their age (e.g., Koch, D’Mello, \& Sackett, 2015). To assess the external validity of our study, additional groups of students beyond those in introductory psychology should be examined.

Students who reviewed professors in this study merely viewed pictures and heard a brief lecture. We recognize that the dynamic nature of a classroom is much more complex, limiting our external validity. For example, with limited teacher information, participants may have relied heavily on perceptions of physical attributes to make inferences about rapport and effectiveness. In the richness of classroom environments, students have additional information based on social interactions, perhaps creating a different pattern of results. However, a manipulated empirical study allows us to identify experimentally an ongoing bias in student evaluations. Such information illustrates the need for caution when depending on student evaluations for faculty tenure, promotion, raises, and awards. As long as gender and age bias exists in the minds of students, discrimination can occur.

\section{References}

Abramson, A., \& Silverstein, M. (2004). Images of aging in America 2004. Retrieved December 18, 2014, from http://assets.aarp.org/rgcenter/general/images_aging.pdf

Allport, G. W. (1954). The nature of prejudice. New York: Addison-Wesley. 
Joye, S. and Wilson, J.

Arbuckle, J., \& Williams, B. D. (2003). Students' perceptions of expressiveness: Age and gender effects on teacher evaluations. Sex Roles, 49(9/10), 507-516. doi: 10.1023/A:1025832707002

Bargh, J. A., Chen, M., \& Burrows, L. (1996). Automaticity of social behavior: Direct effects of trait concept and stereotype activation on action. Journal of Personality and Social Psychology, 71(2), 230-244. http://dx.doi.org/10.1037/0022-3514.71.2.230

Bornstein, R. F. (1989). Exposure and affect: Overview and meta-analysis of research, 19681987. Psychological Bulletin, 106, 265-289. http://dx.doi.org/10.1037/0033-2909.106.2.265

Danziger, P. R., \& Welfel, E. R. (2000). Age, gender, and health bias in counselors: An empirical analysis. Journal of Mental Health Counseling, 22, 135-149.

Dion, K. E., Berscheid \& Walster, E. (1972). What is beautiful is good. Journal of Personality and Social Psychology, 24(3), 285-290. http://dx.doi.org/10.1037/0033-2909.110.1.109

Ebert, I. D., Steffans, M. C., \& Kroth, A. (2014). Warm, but maybe not to competent?Contemporary implicit stereotypes of women and men in Germany. Sex Roles, 70(9-10), 359375. doi: 10.1007/s11199-014-0369-5

Felton, J., Koper, P. T., Mitchell, J., \& Stinson, M. (2008). Attractiveness, easiness, and other issues: Student evaluations of professors on Ratemyprofessors.com. Assessment and Evaluation in Higher Education, 33(1), 45-61. doi: 10.1080/02602930601122803

Felton, J., Mitchell, J., \& Stinson, M. (2004). Web-based student evaluations of professors: The relations between perceived quality, easiness, and sexiness. Assessment and Evaluation in Higher Education, 29(1), 91-108. doi: 10.1080/0260293032000158180

Freng, S., \& Webber, D. (2009). Turning up the heat on online teaching evaluations: Does "hotness” matter? Teaching of Psychology, 36, 189-193. doi: 10.1080/00986280902959739

Goebel, B. L., \& Cashen, V. M. (1979). Age, sex, and attractiveness as factors in student ratings of teachers: A developmental study. Journal of Educational Psychology, 71(5), 646-653. http://dx.doi.org/10.1037/0022-0663.71.5.646

Gurung, R. A. R., \& Vespia, K. (2007). Looking good, teaching well? Linking liking, looks, and learning. Teaching of Psychology, 34(1), 5-10. doi: 10.1080/00986280709336641

Hamermesh, D. S., \& Parker, A. (2005). Beauty in the classroom: Instructors' pulchritude and putative pedagogical productivity. Economics of Education Review, 24, 369-376. doi: 10.1016/j.econedurev.2004.07.013

Horner, K. L., Murray, H. G., \& Rushton, J. P. (1989). Relation between aging and rated teaching effectiveness of academic psychologists. Psychology and Aging, 4(2), 226-229. http://dx.doi.org/10.1037/0882-7974.4.2.226 
Joye, S. and Wilson, J.

Kierstead, D., D’Agostino, P., \& Dill, H. (1988). Sex role stereotyping of college professors: Bias in students' ratings of instructors. Journal of Educational Psychology, 80(3), 342-344. http://dx.doi.org/10.1037/0022-0663.80.3.342

Kock, A. J., D’Mello, S. D., \& Sackett, P. R. (2015). A meta-analysis of gender stereotypes and bias in experimental simulations of employment decision making. Journal of Applied Psychology, 100(1), 128-161. http://dx.doiorg/10.1037/a0036734

Legg, A. M., \& Wilson, J. H. (2009). Email from professor enhances student motivation and attitudes. Teaching of Psychology, 36, 205-211. doi: 10.1080/00986280902960034

Löckenhoff, C. E., Chan, W., McCrae, R. R., De Fruyt, F., Jussim, L., De Bolle, M., et al. (2014). Gender stereotypes of personality: Universal and accurate? Journal of Cross-Cultural Psychology, 45(5), 675-694. doi: 10.1177/0022022113520075

Lucăcel, R., \& Băban, A. (2014). Young peoples’ perspective regarding aging. Cognition, Brain, Behavior. An International Journal, 18(2), 151-161.

Marsh, H. W., \& Roche, L. A. (1997). Making student evaluations of teaching effectiveness effective: The critical issues of validity, bias, and utility. American Psychologist, 52(11), 11871197. http://dx.doi.org/10.1037/0003-066X.52.11.1187

Remedios, R., \& Lieberman, D. A. (2008). I liked your course because you taught me well: The influence of grades, workload, expectations, and goals on students' evaluations of teaching. British Educational Research Journal, 34(1), 91-115. doi: 10.1080/01411920701492043

Riniolo, T. C., Johnson, K. C., Sherman, T. R., \& Misso, J. A. (2006). Hot or not: Do professors perceived as physically attractive receive higher student evaluations? The Journal of General Psychology, 133(1), 19-35. doi: 10.3200/GENP.133.1.19-35

Ryan, R., \& Wilson, J. H. (2014). Professor-Student Rapport Scale: Psychometric properties of the brief version. Journal of the Scholarship of Teaching and Learning, 14(3), 64-74.

Sarwer, D. B., Grossbart, T. A., \& Didie, E. R. (2003). Beauty and society. Seminars in Cutaneous Medicine and Surgery, 22(2), 79-92.

Sprague, J., \& Massoni, K. (2005). Student evaluations and gendered expectations: What we can’t count can hurt us. Sex Roles, 53(11/12), 779-793. doi: 10.1007/s11199-005-8292-4

Wilson, J. H., Beyer, D., \& Monteiro, H. (2014). Professor age affects student ratings: Halo effect for younger teachers. College Teaching, 62, 20-24. doi: 10.1080/87567555.2013.825574

Wilson, J. H., Stadler, J. R., Schwartz, B. M., \& Goff, D. M. (2009). Touching your students: The impact of a handshake on the first day of class. Journal of the Scholarship of Teaching and Learning, 9(1), 108-117. 
Joye, S. and Wilson, J.

Wilson, J. H., \& Ryan, R. G. (2013). Student-teacher rapport scale: Six items predict student outcomes. Teaching of Psychology, 40, 130-133.

Wilson, J. H., \& Wilson, S. B. (2007). The first day of class affects student motivation: An experimental study. Teaching of Psychology, 34, 226-230. doi: 10.1080/00986280701700151

Zajonc, R. B. (1968) Attitudinal effects of mere exposure. Journal of Personality and Social Psychology Monographs, 9(2, Pt. 2). http://dx.doi.org/10.1037/h0025848

Zebrowitz, L. A., Olson, K., \& Hoffman, K. (1993). Stability of babyfaceness and attractiveness across the life span. Journal of Personality and Social Psychology, 64(3), 453-466. http://dx.doi.org/10.1037/0022-3514.64.3.453 